\title{
Influence of Chemical Admixtures on Fresh and Hardened Properties of Prolonged Mixed Concrete
}

\author{
Tarek Uddin Mohammed, ${ }^{1}$ Tanvir Ahmed, ${ }^{1}$ Shibly Mostafiz Apurbo, ${ }^{1}$ Tahir Absar Mallick, ${ }^{1}$ \\ Farhan Shahriar, ${ }^{2}$ Abdul Munim, ${ }^{2}$ and Mohammad Abdul Awal ${ }^{3}$ \\ ${ }^{1}$ Department of Civil and Environmental Engineering, Islamic University of Technology (IUT), Gazipur 1704, Bangladesh \\ ${ }^{2}$ Housing and Building Research Institute (HBRI), Dhaka 1216, Bangladesh \\ ${ }^{3}$ Structural Engineers Limited (SEL), West Panthapath, Dhaka 1209, Bangladesh
}

Correspondence should be addressed to Tanvir Ahmed; tanvirbd@iut-dhaka.edu

Received 4 July 2017; Accepted 25 October 2017; Published 17 December 2017

Academic Editor: Jose M. Monzo

Copyright (C) 2017 Tarek Uddin Mohammed et al. This is an open access article distributed under the Creative Commons Attribution License, which permits unrestricted use, distribution, and reproduction in any medium, provided the original work is properly cited.

\begin{abstract}
Effects of different chemical admixtures on fresh and hardened properties of prolonged mixed concrete and their costeffectiveness were investigated. Influence of sand to aggregate volume ratio, cement content, and use of chilled mixing water on the properties of prolonged mixed concrete was studied as well. Different concrete mixtures were prepared using five different types of chemical admixture (one water reducer based on lignosulfonate and four superplasticizers based on sulfonated naphthalene polymer, polycarboxylic ether, second-generation polycarboxylic ether polymer, and organic polymer), varying s/a ratio $(0.40$ and 0.45$)$ and cement content $\left(340 \mathrm{~kg} / \mathrm{m}^{3}\right.$ and $\left.380 \mathrm{~kg} / \mathrm{m}^{3}\right)$ and using chilled mixing water. Slump tests were performed at 15-minute intervals to assess the fresh performance of each prolonged mixed concrete mixture. $100 \mathrm{~mm}$ by $200 \mathrm{~mm}$ cylindrical concrete specimens were prepared and tested for compressive strength, Young's modulus, splitting tensile strength, and ultrasonic pulse velocity. Results indicate that concretes with sulfonated naphthalene polymer-based superplasticizer and second-generation polycarboxylic ether-based superplasticizer show best performances in both fresh and hardened states. Concrete with lignosulfonate-based water reducer exhibits poor performance in comparison with the concretes with superplasticizers. The cost per unit compressive strength of concrete with sulfonated naphthalene polymer-based superplasticizer is lower compared with the concretes with other types of chemical admixture.
\end{abstract}

\section{Introduction}

In recent years, the demand for ready-mix concrete (RMC) has increased rapidly in Dhaka city. The primary reasons behind this are convenience of using RMC in high-rise structures, shortage of space at construction site, saving of time related to the preparation of concrete on-site, and better quality of RMC compared to the conventional concrete. Nevertheless, because of heavy traffic congestions throughout Dhaka, especially during weekdays, the time required to haul RMC from plant to construction site is very high. Therefore, keeping concrete workable for such a long time without compromising the required strength has become one of the most challenging tasks in the RMC industry. Moreover, high ambient temperature in summer makes the situation worse, since high temperature adversely affects the workability of fresh concrete [1-5]. Selection of appropriate type and dosage of chemical admixture can play an important role in this regard.

A good number of researches were carried out to understand the effects of different types of chemical admixture on properties of concrete. For instance, Topçu and Ateşin [6] compared the slump flow results of concretes made with lignosulfonate-based admixture and naphthalenesulfonate-based admixture; their results indicate that naphthalenesulfonate-based admixture imparts better flowability to concrete compared to lignosulfonatebased admixture. Sugamata et al. [7] investigated the effect of chemical structure of polycarboxylic ether-based admixture on fresh performance of concrete and found that 
TABle 1: Properties and recommended ranges of dosage of chemical admixtures.

\begin{tabular}{lcccc}
\hline $\begin{array}{l}\text { Chemical } \\
\text { admixture }\end{array}$ & Composition & Appearance & $\begin{array}{c}\text { Specific gravity } \\
\text { at 25 } 5^{\circ} \text { C }\end{array}$ & $\begin{array}{c}\text { Recommended dosage } \\
\text { range (\% weight of cement) }\end{array}$ \\
\hline WR & Lignosulfonate based & Dark brown liquid & 1.17 & $0.23-0.47$ \\
SP1 & Sulfonated naphthalene polymer based & Dark brown liquid & 1.24 & $0.87-2.23$ \\
SP2 & Polycarboxylic ether based & Light brown liquid & 1.05 & $0.42-1.26$ \\
SP3 & Second-generation polycarboxylic ether & Light brown liquid & 1.10 & $0.55-1.32$ \\
SP4 & polymer based & Dark brown liquid & 1.19 & $0.71-1.31$ \\
\hline
\end{tabular}

polycarboxylic ether molecule with long side chains improved the fresh performance of concrete. Mardani-Aghabaglou et al. [8] studied different types of polycarboxylic etherbased admixture and observed that polycarboxylic etherbased admixture with low side chain density imparted high flowability to concrete. Papayianni et al. [9] studied the compressive strengths of concretes made with different admixtures and observed that the admixture based on modified polycarboxylic ether polymer imparted higher compressive strength to concrete compared to the admixtures based on sulfonated polymer and synthetic polymer at the end of 28 days. In another study, Mohammed and Hamada [10] examined the long-term behaviors of concrete made with chemical admixture having polycarboxyl group and concrete made with chemical admixture having naphthalene group in tidal environment. They observed, after 10 years, chemical admixture having naphthalene group imparted higher compressive strength as well as higher Young's modulus to concrete in comparison with admixture having polycarboxyl group. They also observed that the chloride ingress was higher in concrete made with admixture having polycarboxyl group compared to the concrete made with admixture having naphthalene group.

Although numerous studies were conducted with different types of chemical admixture, very few of them addressed the influence of chemical admixtures on properties of prolonged mixed concrete [11-16]. Nevertheless, most of the studies [11-15] did not address the influence of chemical admixtures on Young's modulus and tensile strength of concrete subjected to prolonged mixing. Moreover, most of the chemical admixtures studied in [11-13, 15] are old-generation plasticizers and are less commonly used in the RMC industry at present. Mohammed et al. [16] studied the effects of different types of chemical admixture on several mechanical properties of prolonged mixed concrete (e.g., compressive strength, Young's modulus, and splitting tensile strength). However, the effects of chemical admixtures on concrete properties at different dosages and for different mix design parameters (e.g., sand to aggregate volume (s/a) ratio and cement content $(\mathrm{C})$ ) are yet essential to be investigated.

With the viewpoint of the above discussion, a detailed experimental investigation has been carried out with some chemical admixtures which are used extensively in the ready-mix concrete industry of Bangladesh. The effects of these admixtures and their dosages on fresh properties (workability) and hardened properties (compressive strength, Young's modulus, splitting tensile strength, and ultrasonic pulse velocity (UPV)) of concrete have been studied so as to identify the best type of chemical admixture. The costeffectiveness of using the chemical admixtures in concrete has also been analyzed. The effects of sand to aggregate volume (s/a) ratio, cement content (C), and use of chilled mixing water on fresh and hardened properties of prolonged mixed concrete have been investigated as well.

\section{Experimental Method}

2.1. Material Properties. In this study, five different types of chemical admixture were used. One of the admixtures was water reducer (WR) and the rest four were superplasticizers (SP1, SP2, SP3, and SP4). All the types of chemical admixture comply with ASTM C494. The chemical and physical properties of the chemical admixtures, and their dosage ranges as recommended by the manufacturers for the best performance, are mentioned in Table 1. Crushed stones were used as a coarse aggregate in concrete. The maximum size of the coarse aggregate was $19 \mathrm{~mm}$. Natural river sand was used as a fine aggregate. Figure 1 shows the gradations of coarse and fine aggregates. Both the gradations of coarse and fine aggregates satisfy ASTM C33 requirements. The physical properties of coarse and fine aggregates are summarized in Tables 2 and 3, respectively. The physical properties of both coarse and fine aggregates were determined as per ASTM guidelines. CEM II/B-M 42.5 cement (as per BDS EN 197-1-2000 [17]) was used as the binding material. The cement contains $75 \%$ clinker and $25 \%$ mineral admixture including ground-granulated blast furnace slag, limestone, fly ash, and gypsum.

2.2. Mixture Proportion and Cases Studied. Seven different types of concrete mixture were prepared for this study, namely, M1, M2, M3, M4, M5, M6, and RM. The ambient temperature was $25^{\circ} \mathrm{C} \pm 2{ }^{\circ} \mathrm{C}$ when the mixtures were prepared. All the mixtures were prepared using a laboratory mixer having a capacity of 751 . Each mixture was initially mixed for 5 minutes at a speed of $20 \mathrm{rpm}$ to ensure its homogeneity. After that, the mixing was carried out at a speed of $6 \mathrm{rpm}$. This low rotational speed was chosen to simulate the mixing process of ready-mix concrete in truck mixer. The mixer was stopped briefly at 15 -minute intervals in order to conduct slump tests. The mixing process of each concrete mixture was continued until the final slump became less than or equal to $2 \mathrm{~cm}$.

Each M1 concrete mixture was prepared using the average of the maximum and minimum dosages of every 


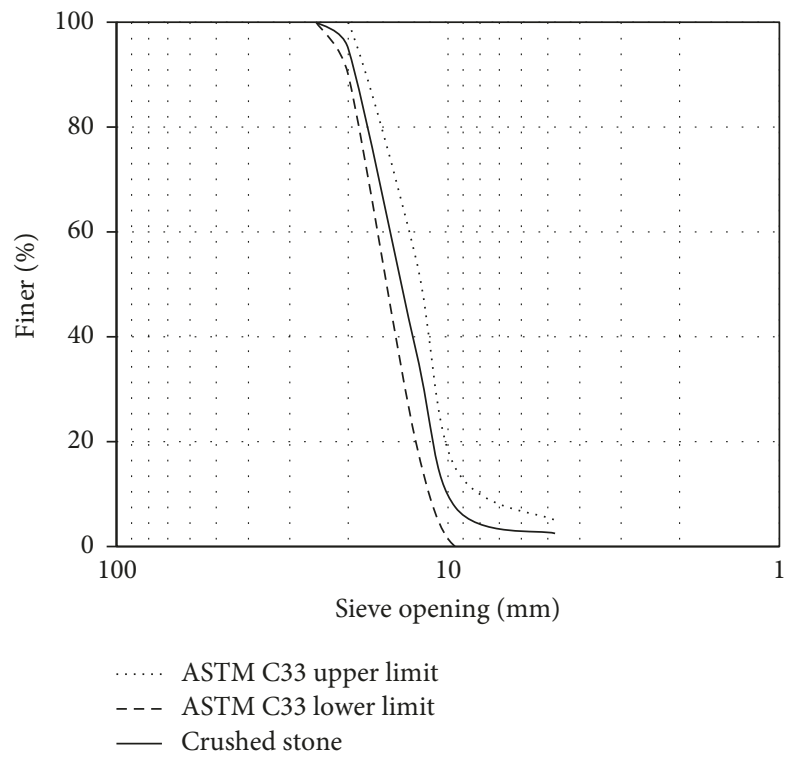

(a)

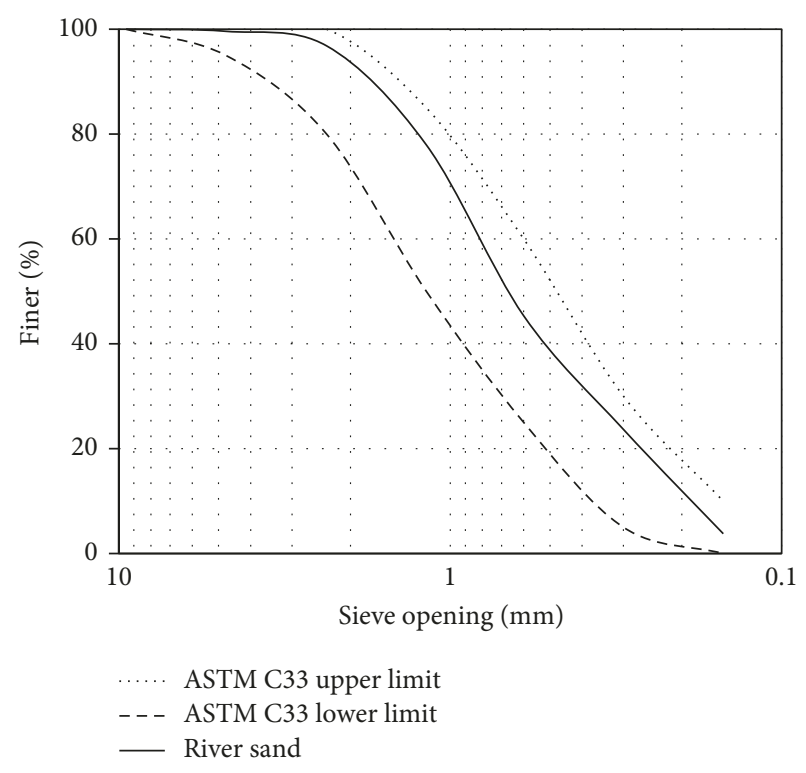

(b)

Figure 1: Gradations of (a) coarse aggregate (crushed stone) and (b) fine aggregate (river sand).

TABle 2: Properties of coarse aggregate.

\begin{tabular}{lccccc}
\hline $\begin{array}{l}\text { Aggregate } \\
\text { type }\end{array}$ & $\begin{array}{c}\text { Specific } \\
\text { gravity }\end{array}$ & $\begin{array}{c}\text { Absorption } \\
\text { capacity (\%) }\end{array}$ & $\begin{array}{c}\text { Abrasion (\%) } \\
\text { (as per ASTM C131) }\end{array}$ & $\begin{array}{c}\text { SSD unit } \\
\text { weight }\left(\mathrm{kg} / \mathrm{m}^{3}\right)\end{array}$ & Fineness modulus \\
\hline Crushed stone & 2.56 & 2.39 & 38.30 & 1549 & Controlled as per ASTM C33 \\
\hline
\end{tabular}

TABle 3: Properties of fine aggregate.

\begin{tabular}{lcccc}
\hline Aggregate type & Specific gravity & Absorption capacity $(\%)$ & SSD unit weight $\left(\mathrm{kg} / \mathrm{m}^{3}\right)$ & Fineness modulus \\
\hline River sand & 2.45 & 3.30 & 1520 & 2.52 \\
\hline
\end{tabular}

chemical admixture recommended by the respective manufacturer. On the other hand, M2, M3, M4, M5, and M6 mixtures were prepared using the maximum recommended dosages of admixtures. During the preparation of M1 and M2 mixtures, the entire dosage of admixture was applied with water at the beginning of mixing. However, in case of M3, M4, M5, and M6 mixtures, the total dosage of admixture was applied in two stages: at first, $2 / 3$ of the dosage of admixture was applied with water, and the rest $1 / 3$ was applied when the slump value of prolonged mixed concrete became less than or equal to $3 \mathrm{~cm}$.

In M1, M2, and M3 mixtures, the water to cement (W/C) ratio, s/a ratio, and cement content $(\mathrm{C})$ were, respectively, 0.40 , 0.40 , and $340 \mathrm{~kg} / \mathrm{m}^{3}$. In M4 mixture, the s/a ratio was increased to 0.45 , but the $\mathrm{W} / \mathrm{C}$ ratio and cement content were kept similar to M1, M2, and M3 mixtures. In M5 and M6 mixtures, the cement content was raised to $380 \mathrm{~kg} / \mathrm{m}^{3}$ of concrete, but $\mathrm{W} / \mathrm{C}$ and s/a ratios were kept, respectively, to 0.40 and 0.40 . In the RM (reference mix), no chemical admixture was used, and the $\mathrm{W} / \mathrm{C}$ ratio, s/a ratio, and cement content were, respectively, $0.40,0.40$, and $340 \mathrm{~kg} / \mathrm{m}^{3}$. Prior to the preparation of each mixture, both the coarse and fine aggregates were brought to saturated surface dry (SSD) condition, so that the $\mathrm{W} / \mathrm{C}$ ratio of the mix would remain unaffected.
In case of M6 mixture, instead of using plain water, chilled water was used (half of the total required water (by weight) as per mix design was plain water and the rest half was ice) to keep the temperature of the concrete mix low. The initial temperature of the chilled water was $0^{\circ} \mathrm{C} \pm 1^{\circ} \mathrm{C}$. It should be noted that, in M4, M5, and M6 mixtures, only the two types of admixture that gave best performances in M1, M2, and M3 mixtures were used. The details of different types of mixture are presented in Table 4.

Cylindrical concrete specimens of $100 \mathrm{~mm}$ diameter and $200 \mathrm{~mm}$ height were made for assessing the hardened properties of concrete. A total of 22 independent cases and 242 specimens were investigated. The mixture proportions of all 22 cases are summarized in Table 5.

2.3. Specimen Preparation and Test Setup. All the concrete mixtures with chemical admixtures (namely, M1, M2, M3, M4, M5, and M6) were subjected to prolonged mixing. Slump tests were done for concrete mixtures subjected to prolonged mixing at 15-minute intervals as per ASTM C143. When the slump of each mixture became less than or equal to $2 \mathrm{~cm}$, the mixing process was stopped, and the mixture was poured into cylindrical molds to prepare $100 \mathrm{~mm}$ by 
TABle 4: Details of different types of concrete mixture.

\begin{tabular}{|c|c|}
\hline Mix type & Details \\
\hline M1 & $\mathrm{W} / \mathrm{C}=0.40 ; \mathrm{s} / \mathrm{a}=0.40 ; C=340 \mathrm{~kg} / \mathrm{m}^{3} ;$ average admixture dosage \\
\hline M2 & $\mathrm{W} / \mathrm{C}=0.40 ; \mathrm{s} / \mathrm{a}=0.40 ; C=340 \mathrm{~kg} / \mathrm{m}^{3} ;$ maximum admixture dosage \\
\hline M3 & $\begin{array}{c}\mathrm{W} / \mathrm{C}=0.40 ; \mathrm{s} / \mathrm{a}=0.40 ; C=340 \mathrm{~kg} / \mathrm{m}^{3} ; \text { maximum admixture dosage in two stages: } 2 / 3 \text { at the beginning and } 1 / 3 \\
\text { when slump } \leq 3 \mathrm{~cm}\end{array}$ \\
\hline M4 & $\begin{array}{c}\mathrm{W} / \mathrm{C}=0.40 ; \mathrm{s} / \mathrm{a}=0.45 ; C=340 \mathrm{~kg} / \mathrm{m}^{3} ; \text { maximum admixture dosage in two stages: } 2 / 3 \text { at the beginning and } 1 / 3 \\
\text { when slump } \leq 3 \mathrm{~cm}\end{array}$ \\
\hline M5 & $\begin{array}{c}\mathrm{W} / \mathrm{C}=0.40 ; \mathrm{s} / \mathrm{a}=0.40 ; C=380 \mathrm{~kg} / \mathrm{m}^{3} ; \text { maximum admixture dosage in two stages: } 2 / 3 \text { at the beginning and } 1 / 3 \\
\text { when slump } \leq 3 \mathrm{~cm}\end{array}$ \\
\hline M6 & $\begin{array}{c}\mathrm{W} / \mathrm{C}=0.40 ; \mathrm{s} / \mathrm{a}=0.40 ; C=380 \mathrm{~kg} / \mathrm{m}^{3} ; \text { maximum admixture dosage in two stages: } 2 / 3 \text { at the beginning and } 1 / 3 \\
\text { when slump } \leq 3 \mathrm{~cm} \text {; chilled water used }(1 / 2 \text { of the total water (by weight) was ice) }\end{array}$ \\
\hline RM (reference mix) & $\mathrm{W} / \mathrm{C}=0.40 ; \mathrm{s} / \mathrm{a}=0.40 ; C=340 \mathrm{~kg} / \mathrm{m}^{3} ;$ no admixture \\
\hline
\end{tabular}

TABLE 5: Mixture proportion of concrete.

\begin{tabular}{|c|c|c|c|c|c|c|c|c|}
\hline \multirow{2}{*}{ Concrete mix type } & \multirow{2}{*}{$\mathrm{W} / \mathrm{C}$} & \multirow{2}{*}{$\mathrm{s} / \mathrm{a}$} & \multirow{2}{*}{$\begin{array}{l}\text { Admixture } \\
\text { type }\end{array}$} & \multicolumn{4}{|c|}{ Unit content $\left(\mathrm{kg} / \mathrm{m}^{3}\right)$} & \multirow{2}{*}{$\begin{array}{l}\text { Admixture dosage } \\
\text { (\% weight of cement) }\end{array}$} \\
\hline & & & & Cement & Sand & Aggregate & Water & \\
\hline \multirow{5}{*}{ M1 } & \multirow{15}{*}{0.40} & \multirow{5}{*}{0.40} & WR & 340 & 721 & 1130 & 136 & 0.35 \\
\hline & & & SP1 & 340 & 718 & 1125 & 136 & 1.55 \\
\hline & & & SP2 & 340 & 719 & 1127 & 136 & 0.84 \\
\hline & & & SP3 & 340 & 719 & 1127 & 136 & 0.94 \\
\hline & & & SP4 & 340 & 719 & 1127 & 136 & 1.01 \\
\hline \multirow{5}{*}{ M2 } & & \multirow{5}{*}{0.40} & WR & 340 & 721 & 1130 & 136 & 0.47 \\
\hline & & & SP1 & 340 & 716 & 1122 & 136 & 2.23 \\
\hline & & & SP2 & 340 & 718 & 1125 & 136 & 1.26 \\
\hline & & & SP3 & 340 & 718 & 1125 & 136 & 1.32 \\
\hline & & & $\mathrm{SP} 4$ & 340 & 718 & 1126 & 136 & 1.31 \\
\hline \multirow{5}{*}{ M3 } & & \multirow{7}{*}{0.45} & WR & 340 & 721 & 1130 & 136 & 0.47 \\
\hline & & & SP1 & 340 & 716 & 1122 & 136 & 2.23 \\
\hline & & & SP2 & 340 & 718 & 1125 & 136 & 1.26 \\
\hline & & & SP3 & 340 & 718 & 1125 & 136 & 1.32 \\
\hline & & & $\mathrm{SP} 4$ & 340 & 718 & 1126 & 136 & 1.31 \\
\hline \multirow{2}{*}{ M4 } & & & SP1 & 340 & 806 & 1029 & 136 & 2.23 \\
\hline & & & SP3 & 340 & 808 & 1032 & 136 & 1.32 \\
\hline \multirow{2}{*}{ M5 } & & \multirow{2}{*}{0.40} & SP1 & 380 & 686 & 1075 & 152 & 2.23 \\
\hline & & & SP3 & 380 & 688 & 1079 & 152 & 1.32 \\
\hline \multirow{2}{*}{ M6 } & & \multirow{2}{*}{0.40} & SP1 & 380 & 686 & 1075 & 152 & 2.23 \\
\hline & & & SP3 & 380 & 688 & 1079 & 152 & 1.32 \\
\hline RM (reference mix) & & 0.40 & - & 340 & 722 & 1132 & 136 & - \\
\hline
\end{tabular}

Total number of cases $=22$

Cylinders per case $=3 \times 3$ (compressive strengths at 7 days, 28 days, and 90 days $)+2$ (splitting tensile strengths at 28 days) $=11$

Total number of cylinders $=11 \times 22=242$

$200 \mathrm{~mm}$ cylindrical concrete specimens. After casting of concrete specimens, they were cured initially for 24 hours by covering the cylindrical molds with wet clothes and polythene to prevent moisture loss. The specimens were demolded after 24 hours of casting and then cured under water till the age of testing as per ASTM C31.

The cylindrical specimens were tested for compressive strength and Young's modulus at 7 days, 28 days, and 90 days and for splitting tensile strength at 28 days according to ASTM specifications. Prior to compressive strength test, the UPV test was conducted for unloaded water-saturated concrete specimens according to ASTM C597.

\section{Results and Discussions}

3.1. Fresh Properties of Concrete. According to the JSCE 2007 guidelines for concrete [18], for normal weight ready-mix concrete, the minimum slump requirement at the place of unloading is $8 \mathrm{~cm}$. Therefore, in this study, the workability of each concrete mix was judged based on the time up to which the slump value was greater than $8 \mathrm{~cm}$. The more the time, the better the workability.

3.1.1. Influence of Chemical Admixture Type. The slump test results of RM, M1, M2, and M3 mixtures at 15-minute 

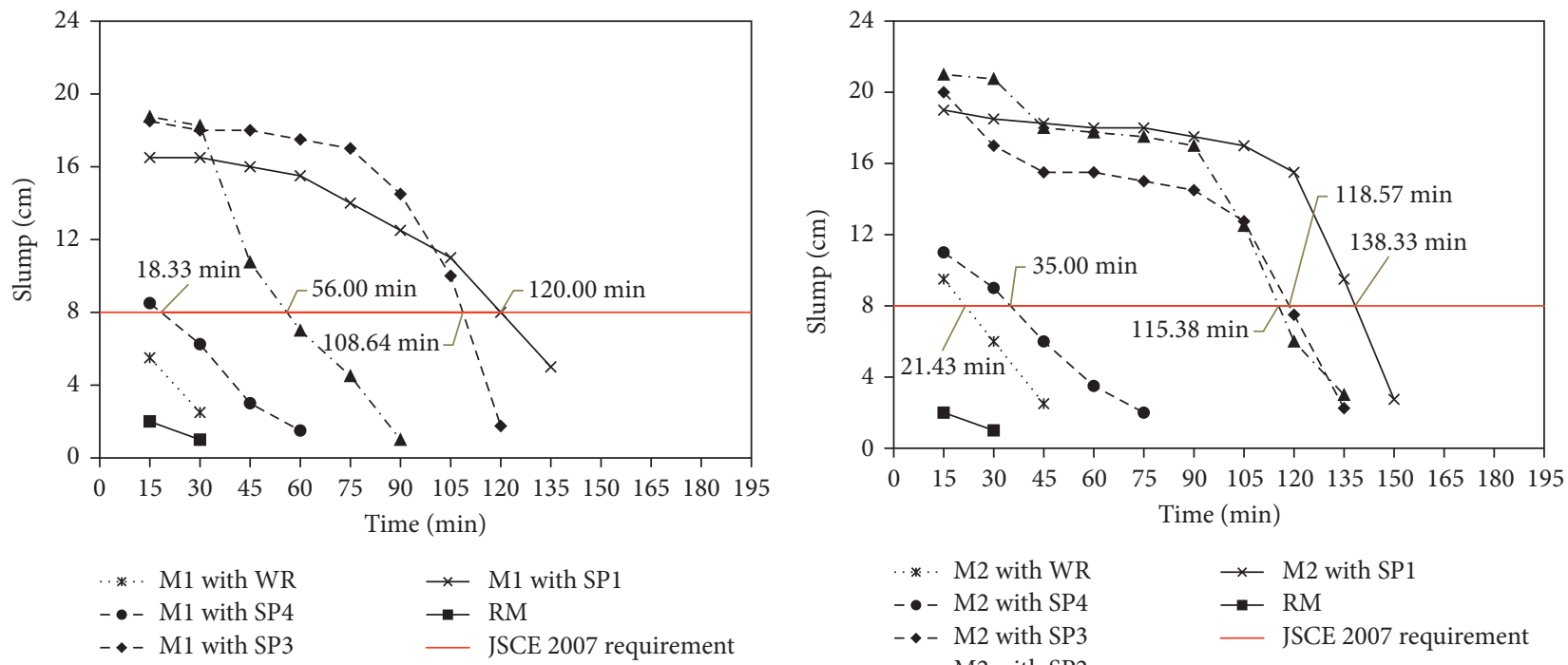

*.. M1 with WR

- - M1 with SP4

$-\bullet$ M1 with SP3

- - M1 with SP2

$$
\begin{aligned}
& \rightarrow \text { M1 with SP1 } \\
& \rightarrow-\text { RM } \\
& - \text { JSCE } 2007 \text { requirement }
\end{aligned}
$$

(a) (b)

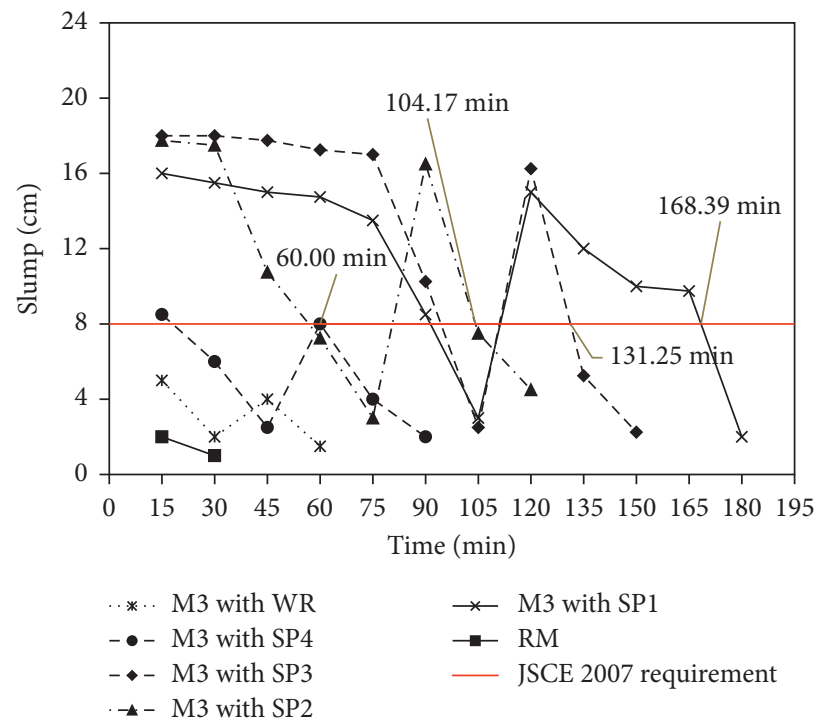

(c)

Figure 2: Slump test results of RM, M1, M2, and M3 mixtures $\left(\mathrm{W} / \mathrm{C}=0.40\right.$, s/a $=0.40$, and $\left.C=340 \mathrm{~kg} / \mathrm{m}^{3}\right):(\mathrm{a}) \mathrm{M} 1=$ average dosage of admixture, $\mathrm{RM}=$ no admixture; (b) M2 = maximum dosage of admixture, $\mathrm{RM}=$ no admixture; (c) M3 = maximum dosage of admixture in two stages, $\mathrm{RM}=$ no admixture.

intervals are presented in Figure 2. Although M1, M2, and M3 concrete mixtures with sulfonated naphthalene polymer-based superplasticizer SP1 resulted in lower initial slumps compared to the mixtures with SP2 and SP3, concrete mixtures with SP1 remained workable for the longest durations. The second best performances were found for M1, M2, and M3 mixtures with second-generation polycarboxylic ether-based superplasticizer SP3. Polycarboxylic ether-based superplasticizer SP2 can be placed in the third position. However, M2 mixture with SP2 performed almost as good as M2 mixture with SP3. Concretes with organic polymer-based SP4 remained workable for shorter durations in comparison with the concretes with other types of superplasticizer. Fresh performances of concretes with superplasticizers were better in comparison with the performances of concrete mixtures with lignosulfonate-based water reducer WR. Results presented in Figure 2 also confirm that M1, M2, and M3 mixtures exhibited better performances in comparison with the reference mix RM (i.e., concrete without chemical admixture).

\subsubsection{Influence of Increased Dosage of Chemical Admixture.} Results presented in Figure 2 show that, for all the types of chemical admixture, M2 mixture remained workable for longer durations compared to M1 mixture (i.e., concrete 
remained workable for longer duration when the dosage of admixture was increased). For instance, in case of M2 mixture with SP3, slump became $8 \mathrm{~cm}$ at the end of 118.57 minutes, whereas in case of M1 concrete with SP3, slump became $8 \mathrm{~cm}$ at the end of 108.64 minutes.

3.1.3. Influence of Two-Stage Dosage of Chemical Admixture. Figure 2 shows that, irrespective of chemical admixture type, M3 mixture remained workable for longer time in comparison with M2 mixture, which implies that concrete would remain workable for longer duration when the dosage of admixture is applied in two stages instead of applying the entire dosage at the beginning of mixing.

3.1.4. Influence of Sand to Aggregate Volume Ratio. The fresh performances of M3, M4, M5, and M6 concrete mixtures with sulfonated naphthalene polymer-based SP1 and second-generation polycarboxylic ether-based SP3 are presented in Figure 3. For both SP1 and SP3, the slump values of M4 concrete mixture were greater than $8 \mathrm{~cm}$ for smaller time period compared to M3 mixture. So, the workability of fresh concrete decreased when the s/a ratio was increased from 0.40 to 0.45 . The reason behind such results may be attributed to the increased volume of fine particles in concrete mix with the increase of s/a ratio. Increased volume of fine particles would increase the surface area; hence, more water would be required to wet this increased area, and consequently the workability of fresh concrete would reduce.

3.1.5. Influence of Cement Content. Figure 3 shows that, for both SP1 and SP3, M5 concrete mixture gave slump values more than $8 \mathrm{~cm}$ for longer period compared to $\mathrm{M} 3$ concrete mixture. The results indicate that, for given $\mathrm{W} / \mathrm{C}$ and s/a ratios, the workability of concrete would increase with the increase of cement content. This is because, for a given $\mathrm{W} / \mathrm{C}$ ratio, the paste content in concrete mix would increase with the increase of cement content which would eventually increase the workability of concrete.

3.1.6. Influence of Using Chilled Mixing Water. From Figure 3 it can be seen that M6 concrete mixture with SP1 and SP3 remained workable for longer durations in comparison with M5 mixture with SP1 and SP3. It can therefore be inferred from the results that the concrete would remain workable for longer time if chilled water is used instead of plain water. The slump of M6 mixture with SP1 became $8 \mathrm{~cm}$ at the end of 265.71 minutes, and the slump of M6 mixture with SP3 became $8 \mathrm{~cm}$ at the end of 222.5 minutes.

\subsection{Hardened Properties of Concrete}

3.2.1. Influence of Chemical Admixture Type. Figure 4 presents the hardened properties of RM, M1, M2, and M3 concretes at the age of 28 days. In all cases, concretes with chemical admixtures resulted in higher compressive strengths, Young's moduli, splitting tensile strengths, and

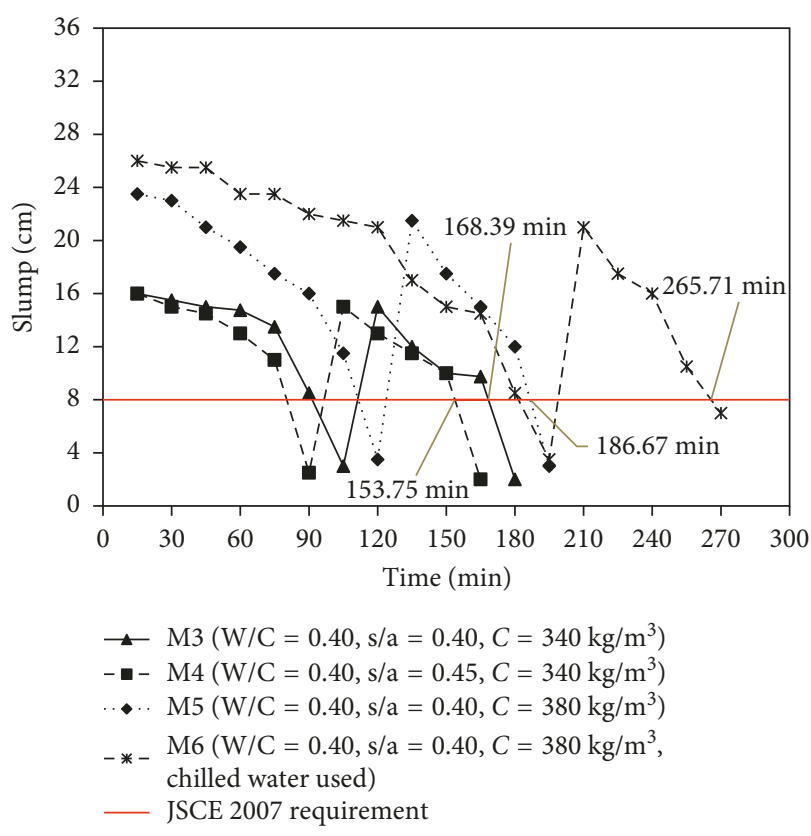

(a)

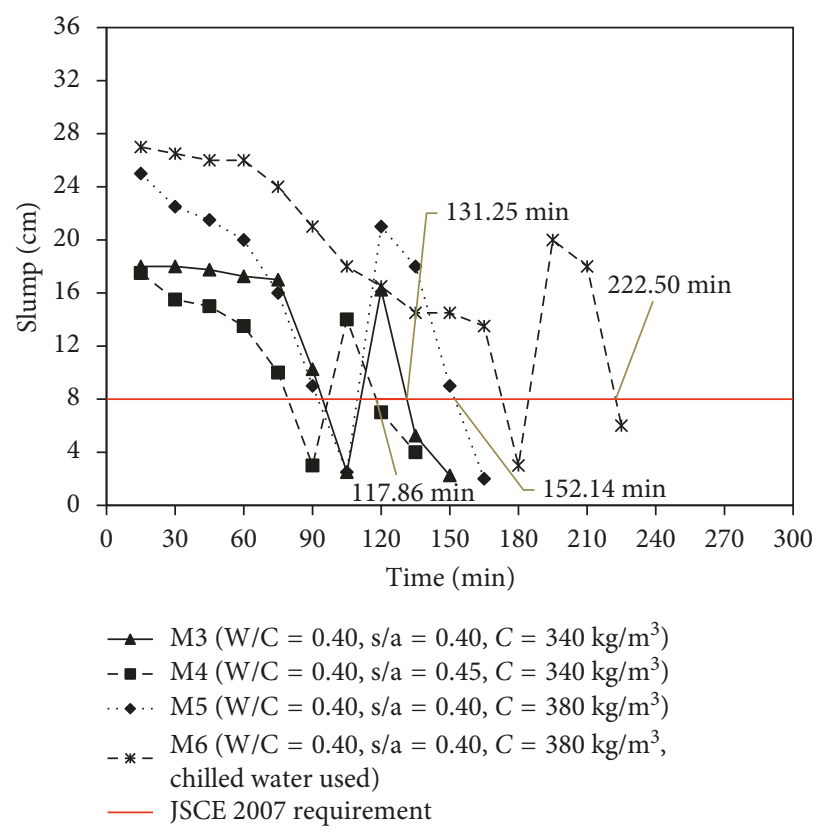

(b)

Figure 3: Slump test results of M3, M4, M5, and M6 mixtures: (a) sulfonated naphthalene polymer-based SP1 (maximum dosage of admixture in two stages) and (b) second-generation polycarboxylic ether-based SP3 (maximum dosage of admixture in two stages).

UPVs compared to the concrete without chemical admixture. Concretes with sulfonated naphthalene polymerbased SP1 and second-generation polycarboxylic etherbased SP3 exhibited better hardened performances in comparison with the concretes with other types of chemical admixture. Concretes with lignosulfonate-based water reducer WR exhibited lower compressive strengths, Young's moduli, splitting tensile strengths, and UPVs 


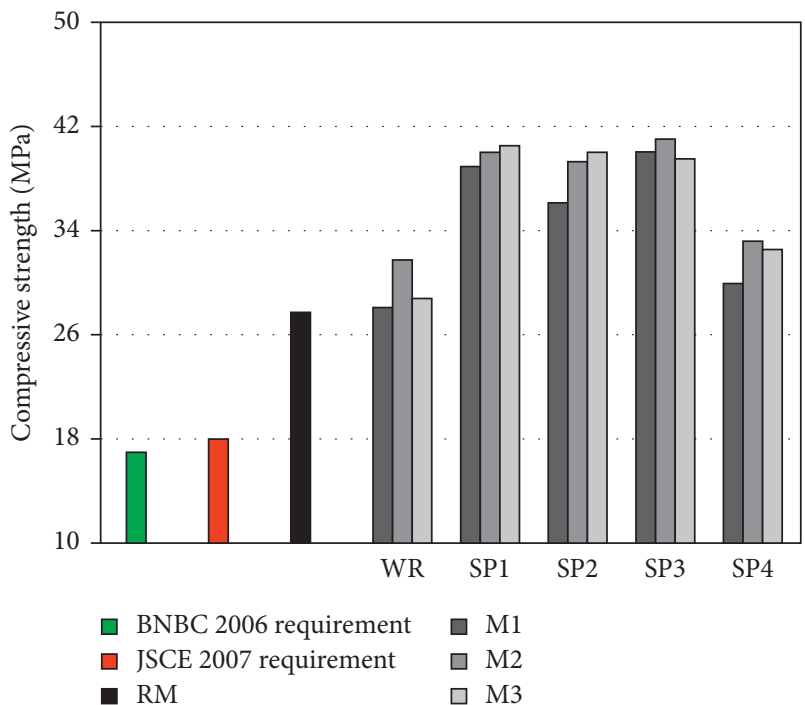

(a)

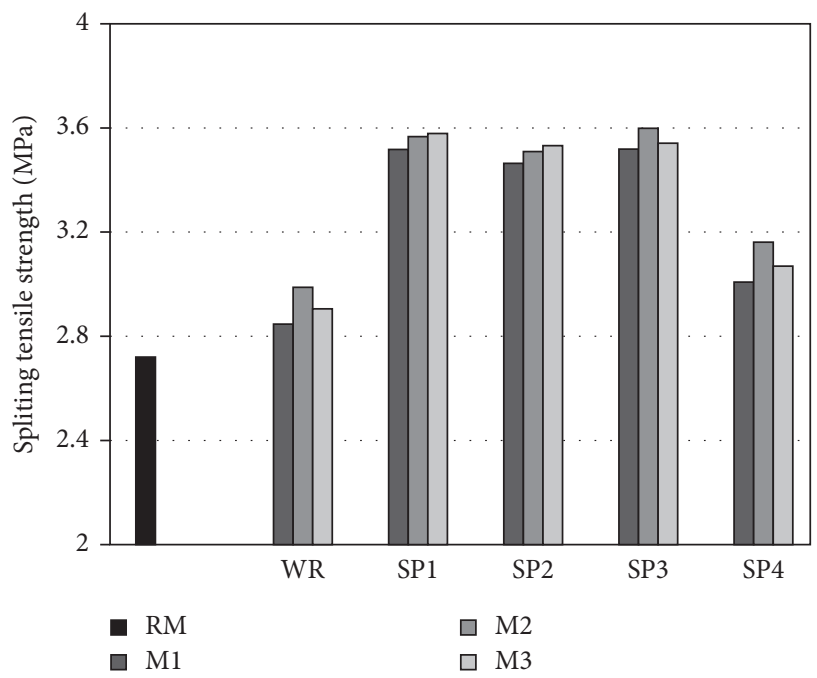

(c)

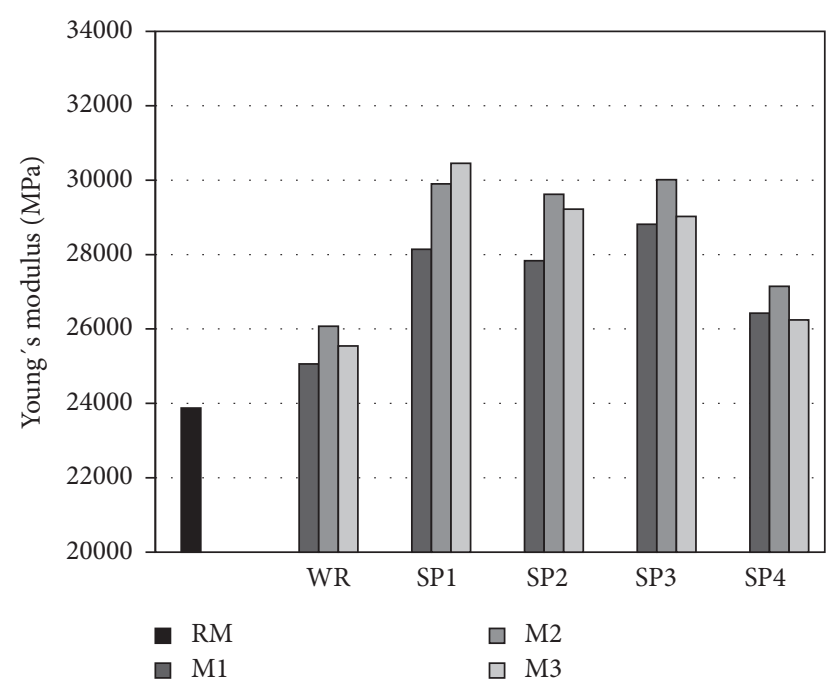

(b)

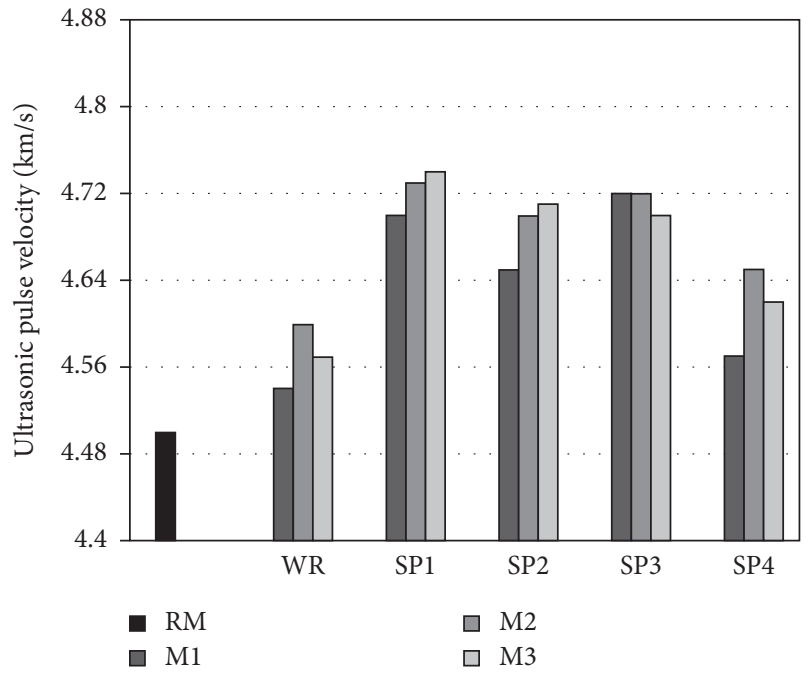

(d)

Figure 4: Hardened properties of RM, M1, M2, and M3 concretes $\left(\mathrm{W} / \mathrm{C}=0.40, \mathrm{~s} / \mathrm{a}=0.40\right.$, and $\left.C=340 \mathrm{~kg} / \mathrm{m}^{3}\right)$ at the age of $28 \mathrm{days}$ : (a) compressive strength, (b) Young's modulus, (c) splitting tensile strength, and (d) ultrasonic pulse velocity.

than the concretes with superplasticizers. The results comply with the conclusions drawn by Rixom and Mailvaganam [19]. Their study indicates that, for a given $\mathrm{W} / \mathrm{C}$, superplasticizers based on sulfonated naphthalene formaldehyde (SMF) and sulfonated melamine formaldehyde (SMF) impart substantially higher compressive strength to concrete in comparison with plasticizers based on lignosulfonate and hydroxycarboxylic acid.

The Bangladesh National Building Code (BNBC) 2006 [20] and JSCE 2007 guidelines for concrete [18] specify the lower limits of 28-day cylindrical compressive strength of normal weight concrete, respectively, to be $17 \mathrm{MPa}$ and $18 \mathrm{MPa}$. Figure 4 shows that, in all cases, concretes with chemical admixtures satisfied the BNBC 2006 [20] and JSCE 2007 [18] requirements.
3.2.2. Influence of Increased Dosage of Chemical Admixture. It can be seen from Figure 4 that, for all types of chemical admixture, M2 concrete resulted in higher compressive strengths, Young's moduli, splitting tensile strengths, and UPVs than M3 concrete. This indicates that the hardened performance of concrete would improve when the dosage of admixture is increased. However, it should be noted that, in no concrete mixture investigated in this study, the dosage of admixture was higher than the maximum dosage recommended by the respective manufacturer. The results conform to the findings obtained by Topçu and Ateşin [6] and Gagné et al. [21]. Their studies imply that, for a given $\mathrm{W} / \mathrm{C}$, the compressive strength and flexural strength of concrete increase with the increase of dosage of chemical admixture up to an optimum limit. Topçu and Ateşin [6] 


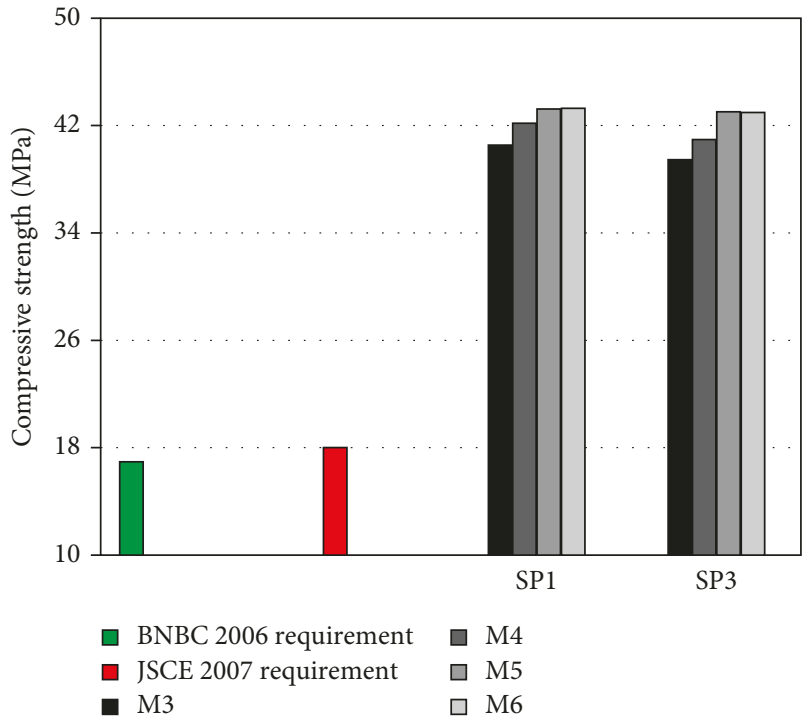

(a)

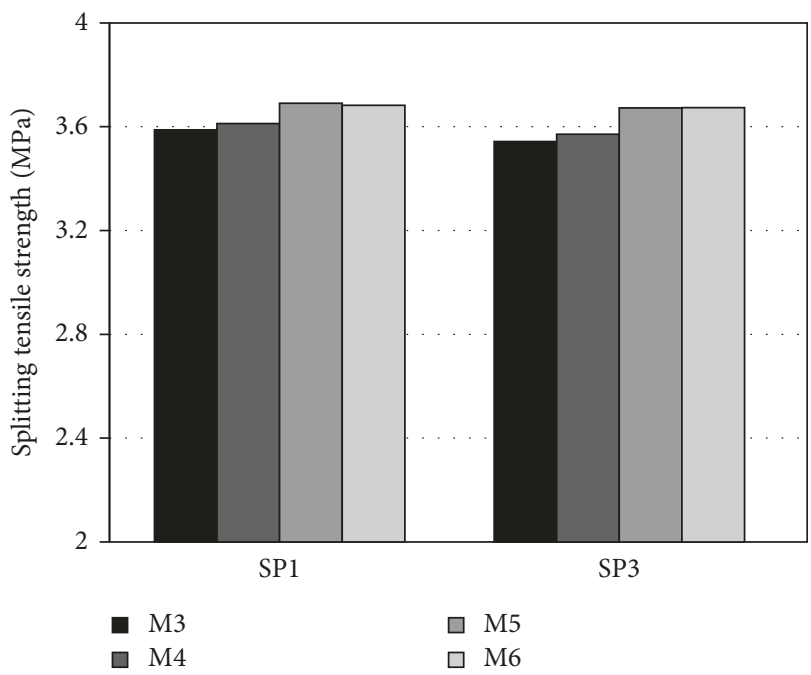

(c)

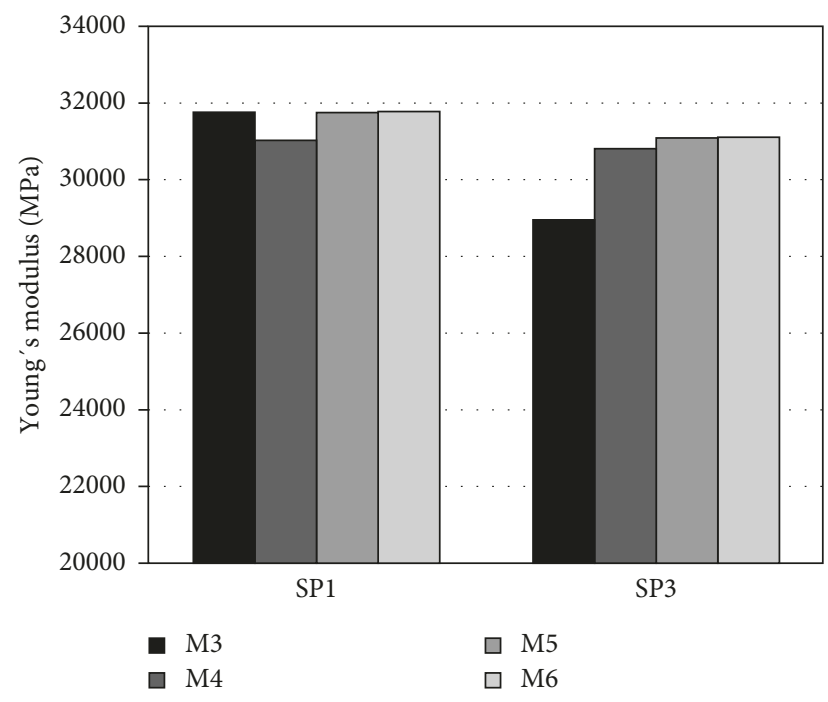

(b)

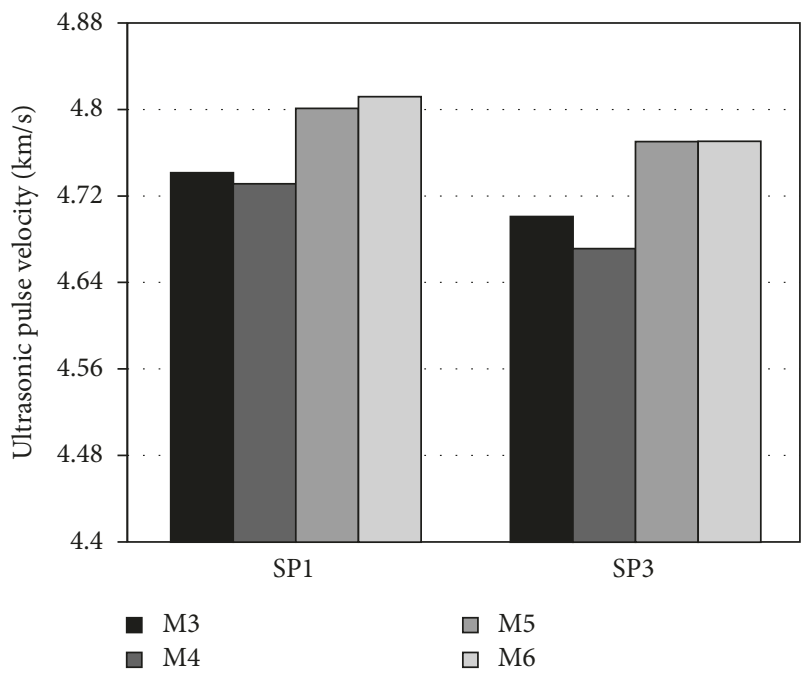

(d)

FIGURE 5: Hardened properties of M3, M4, M5, and M6 concretes at the age of 28 days: (a) compressive strength, (b) Young's modulus, (c) splitting tensile strength, and (d) ultrasonic pulse velocity.

examined the microstructures of concretes made with lignosulfonate and naphthalenesulfonate-based chemical admixtures, by means of a scanning electron microscope (SEM). They found that when the dosage of each chemical admixture was within the optimum limit, concrete with admixture was less porous than the concrete without admixture. The reason behind concrete with admixture exhibiting less porous formations and thus providing improved hardened properties may be attributed to the improved compactibility of concrete.

The present study focused on assessing the fresh and hardened performances of concrete for admixture dosages not exceeding the maximum limits suggested by respective manufacturers. Therefore, the study did not address the influence of overdosing of admixture on concrete properties. Nevertheless, the study conducted by Gagné et al. [21] suggests that dosing of admixture in concrete beyond an optimum limit may deteriorate the physical properties of concrete. This is because overdosing of chemical admixture may result in internal bleeding, which may reduce the quality of paste-aggregate interface.

\subsubsection{Influence of Two-Stage Dosage of Chemical Admixture.} Figure 4 shows that, although for some chemical admixtures, M3 concrete resulted in lower compressive strengths, Young's moduli, splitting tensile strengths, and UPVs compared to M1 and M2 concretes; in all cases, the compressive strengths, Young's moduli, splitting tensile strengths, and UPVs were higher than those resulted by RM concrete. Hence, it can be inferred that the hardened performance of concrete having dosage of chemical admixture applied in two stages would be better compared to the concrete without 
chemical admixture. However, the dosage of admixture should be within the range recommended by the manufacturer.

3.2.4. Influence of Sand to Aggregate Volume Ratio. Figure 5 presents the hardened properties of M3, M4, M5, and M6 concretes at the age of 28 days. For both SP1 and SP3, the compressive strengths, Young's moduli, and splitting tensile strengths of M4 concrete were greater than those of M3 concrete. However, the UPVs of M4 concrete were lower compared to M3 concrete. The results therefore indicate that, with the increase of s/a ratio from 0.40 to 0.45 , the compressive strength, Young's modulus, and splitting tensile strength of concrete would increase, but the UPV through concrete would reduce. Similar conclusions were drawn by Lin et al. [22] and Mohammed et al. [23] based on experimental observations.

It should be noted that, with the increase of s/a ratio from 0.40 to 0.45 , the workability of prolonged mixed concrete decreased, but the compressive strength of concrete increased. Therefore, when the workability of ready-mix concrete is of primary concern, it should be kept into consideration that the s/a ratio is not too high. On the other hand, if the strength of concrete is of primary concern, the s/a ratio should not be too low.

Results presented in Figure 5 also show that, for both SP1 and SP3, the 28-day compressive strengths of M4, M5, and M6 concretes satisfy the minimum requirements of the BNBC 2006 [20] and JSCE 2007 [18].

3.2.5. Influence of Cement Content. Figure 5 shows that compressive strengths, Young's moduli, splitting tensile strengths, and UPVs of M5 concrete were greater in comparison with M3 concrete, which implies that the hardened performance of concrete would improve if the cement content is increased.

3.2.6. Influence of Using Chilled Mixing Water. Results presented in Figure 5 show that the 28-day compressive strengths, Young's moduli, splitting tensile strengths, and UPVs of M6 concrete are almost similar to those of M5 concrete. So, the 28-day hardened properties of concrete did not change significantly when chilled water was used instead of plain water. Since use of chilled mixing water would improve the workability of fresh concrete significantly (Figure 3) without compromising its performance in hardened state, it is advisable to use ice partially with water in ready-mix concrete.

3.2.7. Influence of Age of Concrete. Figure 6 shows the compressive strength gains with age, for different types of concrete with sulfonated naphthalene polymer-based superplasticizer SP1. Results show that, for all types of concrete, the rates of strength gain were high before 28 days, beyond 28 days, the strength gain rates became lower. The 7-day strength of M6 concrete with SP1 was slightly lower compared to that of M5 concrete, this is because the reduced temperature of fresh M6 concrete due to the use of chilled

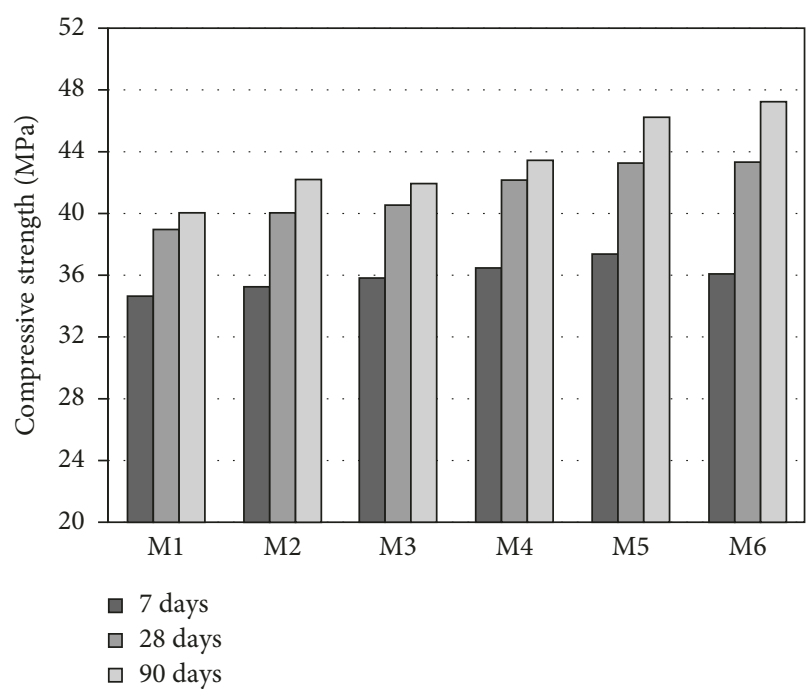

FIGURE 6: Compressive strength gains of different types of concrete made with sulfonated naphthalene polymer-based SP1 with respect to age.

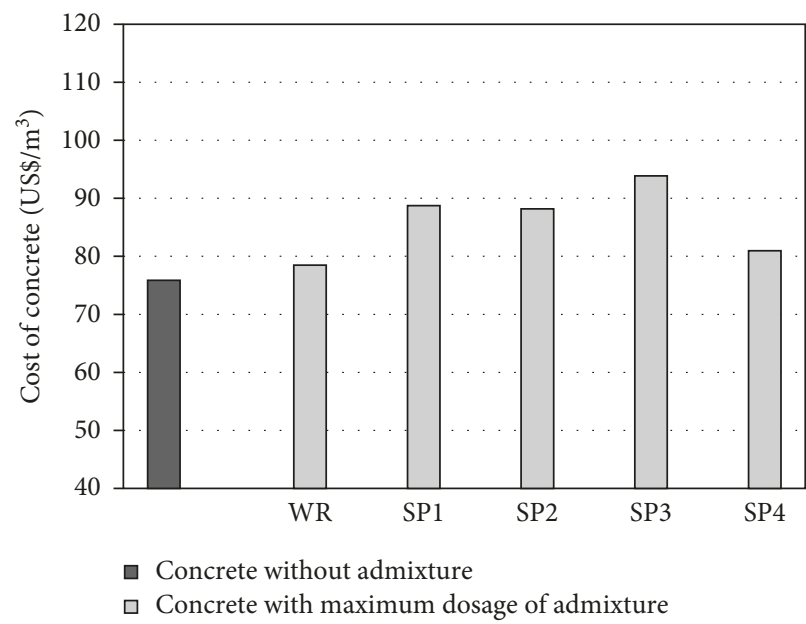

FIgure 7: Costs of $1 \mathrm{~m}^{3}$ of concretes $(\mathrm{W} / \mathrm{C}=0.40, \mathrm{~s} / \mathrm{a}=0.40$, and $C=340 \mathrm{~kg} / \mathrm{m}^{3}$ ) prepared with maximum recommended dosages of different types of chemical admixture.

water delayed the process of strength gain at the early age [24]. However, the 28-day compressive strength of M6 concrete was comparable to that of M5 concrete and the 90-day strength of M6 concrete was slightly higher compared to M5 concrete. The results comply with the conclusions drawn by Price [25] from experimental investigation.

3.3. Cost Analysis. Costs of $1 \mathrm{~m}^{3}$ of concretes made with maximum recommended dosages of different types of chemical admixture and cost of $1 \mathrm{~m}^{3}$ of concrete made without admixture are shown in Figure 7 . It should be noted that the costs presented in Figure 7 were calculated based on the local costs of materials used to prepare per cubic meter of concrete. From Figure 7, lignosulfonate-based water reducer WR seems to be more economical than other admixtures. On the other hand, second-generation 


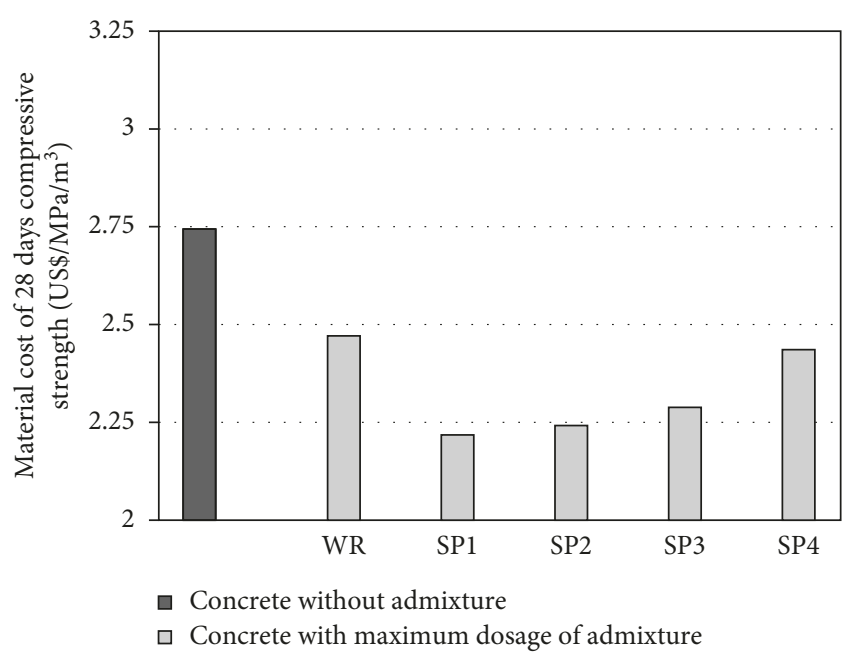

Figure 8: Unit strength costs of $1 \mathrm{~m}^{3}$ of concretes $(\mathrm{W} / \mathrm{C}=0.40$, $\mathrm{s} / \mathrm{a}=0.40$, and $C=340 \mathrm{~kg} / \mathrm{m}^{3}$ ) prepared with maximum recommended dosages of different types of chemical admixture.

polycarboxylic ether-based superplasticizer SP3 seems to be the most expensive one.

The 28-day strengths of concretes prepared with different types of chemical admixture are different. Therefore, the costs per unit 28 -day compressive strength $(1 \mathrm{MPa})$ of $1 \mathrm{~m}^{3}$ concretes prepared with different types of chemical admixture are presented in Figure 8. It can be seen that when the compressive strengths of concretes are taken into account, concrete mixtures with chemical admixtures are found to be more economical compared to the mixture without admixture, sulfonated naphthalene polymer-based superplasticizer SP1 is found to be the most economical admixture, and lignosulfonate-based water reducer WR is found to be the most expensive one.

\section{Conclusions}

From the scope of this investigation, the following conclusions can be drawn:

(1) Sulfonated naphthalene polymer-based superplasticizer shows best performance in improving workability of fresh concrete in comparison with other chemical admixtures. Second-generation polycarboxylic ether-based superplasticizer can be categorized as the second best chemical admixture in improving workability of fresh concrete.

(2) Concretes made with sulfonated naphthalene polymerbased superplasticizer and second-generation polycarboxylic ether-based superplasticizer exhibit higher compressive strengths, splitting tensile strengths, Young's moduli, and UPVs than concretes prepared with other admixtures.

(3) Superplasticizers show better performances in improving fresh and hardened properties of concrete compared to water reducers.

(4) The compressive strength of concrete increases with increase of admixture dosage, when the dosage of admixture is within the range recommended by the manufacturer.

(5) Applying dosage of chemical admixture in two stages helps to keep concrete workable for longer duration compared to applying the same dosage of admixture at the beginning of mixing process.

(6) Workability of fresh concrete decreases with the increase of s/a ratio from 0.40 to 0.45 . However, the compressive strength of concrete increases when the s/a ratio is increased from 0.40 to 0.45 .

(7) If chilled water is used in concrete mix, it remains workable for longer period in comparison with the concrete mix with plain water. Use of chilled water in fresh concrete causes reduction in early concrete strength but improves the long-term strength property of concrete.

(8) Unit strength cost of concrete made with sulfonated naphthalene polymer-based superplasticizer is lower compared to other chemical admixtures.

\section{Conflicts of Interest}

The authors declare that they have no conflicts of interest.

\section{Acknowledgments}

The authors express their sincere gratitude and appreciation to Islamic University of Technology (IUT), Gazipur, Bangladesh, and the Structural Engineers Limited (SEL), Bangladesh, for financing the research project. The cement used in this study was provided by Seven Circle Bangladesh Limited. The authors wish to express their gratitude to Seven Circle Bangladesh Limited as well.

\section{References}

[1] J. G. Munday, "Transportation effects on strength and consistency," in Advanced Ready-Mix Concrete Technologies, R. K. Dhir Ed., pp. 343-353, Pergamon Press, Oxford, UK, 1976.

[2] N. P. Mailvaganam, "Factors influencing slump loss in flowing concrete," ACI Special Publication, vol. 62, pp. 389-404, 1979.

[3] N. Ghafoori and H. Diawara, "Influence of temperature on fresh performance of self-consolidating concrete," Construction and Building Materials, vol. 24, no. 6, pp. 946-955, 2010.

[4] V. Sampebulu, "Influence of high temperatures on the workability of fresh ready-mixed concrete," ITB Journal of Engineering Science, vol. 44, no. 1, pp. 21-32, 2012.

[5] S. Wang, W. K. Guo, and Z. Y. Gao, "Influences of cement temperature on the performance of concrete mixed with superplasticizer," in Advances in Engineering and Technology, L. Xie and D. Huang Eds., pp. 243-250, Taylor \& Francis Group, London, UK, 2014.

[6] I. B. Topçu and Ö. Ateşin, "Effect of High Dosage Lignosulphonate and Naphthalene Sulphonate Based Plasticizer Usage on Micro Concrete Properties," Construction and Building Materials, vol. 120, pp. 189-197, 2016.

[7] T. Sugamata, T. Sugiyama, and A. Ohta, "The effects of a new high-range water-reducing agent on the improvement of rheological properties," in Proceedings of the Seventh 
CANMET/ACI International Conference on Superplasticizers and Other Chemical Admixtures in Concrete, pp. 343-359, Berlin, Germany, October 2003.

[8] A. Mardani-Aghabaglou, M. Tuyan, G. Yilmaz, Ö. Ariöz, and K. Ramyar, "Effect of different types of superplasticizer on fresh, rheological and strength properties of self-consolidating concrete," Construction and Building Materials, vol. 47, pp. 1020-1025, 2013.

[9] I. Papayianni, G. Tsohos, N. Oikonomou, and P. Mavria, "Influence of superplasticizer type and mix design parameters on the performance of them in concrete mixtures," Cement and Concrete Composites, vol. 27, no. 2, pp. 217-222, 2005.

[10] T. U. Mohammed and H. Hamada, "Durability of concrete made with different water-reducing chemical admixtures in tidal environment," ACI Materials Journal, vol. 100, no. 3, pp. 194-202, 2003.

[11] R. F. Adams, P. R. Stodola, and D. R. Mitchell, "Discussion of concrete retempering studies by Hawkins M. J.," ACI Journal Proceedings, vol. 59, pp. 1249-1250, 1962.

[12] D. Ravina, "Retempering of prolonged-mixed concrete with admixtures in hot weather," ACI Journal Proceedings, vol. 72, no. 6, pp. 291-295, 1975.

[13] R. W. Previte, "Concrete slump loss," ACI Journal Proceedings, vol. 74, no. 8, pp. 361-367, 1977.

[14] D. Ravina and I. Soroka, "Slump loss and compressive strength of concrete made with WRR and HRWR admixtures and subjected to prolonged mixing," Cement and Concrete Research, vol. 24, no. 8, pp. 1455-1462, 1994.

[15] A. Baskoca, M. H. Ozkul, and S. Artirma, "Effect of chemical admixtures on workability and strength properties of prolonged agitated concrete," Cement and Concrete Research, vol. 28, no. 5, pp. 737-747, 1998.

[16] T. U. Mohammed, T. Ahmed, T. A. Mallick, F. Shahriar, and A. Munim, "Influence of chemical admixtures on fresh and hardened properties of ready mix concrete," in $1 s t$ International Conference on Engineering Research Practice, A. Rahman, F. Mashiri, M. M. Rahman, and R. Karim Eds., pp. 36-41, STAMCA, Dhaka, Bangladesh, 2017.

[17] BDS EN 197-1, Cement-Part 1: Composition, Specifications and Conformity Criteria for Common Cements, Bangladesh Standards and Testing Institution, Dhaka, Bangladesh, 2003.

[18] JSCE Guidelines for Concrete, Standard Specifications for Concrete Structures, Japan Society of Civil Engineers, Tokyo, Japan, 2007.

[19] M. R. Rixom and N. P. Mailvaganam, Chemical Admixtures for Concrete, E \& FN Spon, London, UK, 3rd edition, 1999.

[20] Bangladesh National Building Code, Housing and Building Research Institute, and Bangladesh Standards and Testing Institution, Dhaka, Bangladesh, 2006.

[21] R. Gagné, A. Boisvert, and M. Pigeon, "Effect of superplasticizer dosage on mechanical properties, permeability, and freeze-thaw durability of high-strength concretes with and without silica fume," ACI Materials Journal, vol. 93, no. 2, pp. 111-120, 1996.

[22] Y. Lin, S.-F. Kuo, C. Hsiao, and C.-P. Lai, "Investigation of pulse velocity-strength relationship of hardened concrete," ACI Materials Journal, vol. 104, no. 4, pp. 344-350, 2007.

[23] T. U. Mohammed and M. N. Rahman, "Effect of types of aggregate and sand-to-aggregate volume ratio on UPV in concrete," Construction and Building Materials, vol. 125, pp. 832-841, 2016.
[24] A. M. Neville, Properties of Concrete, Pearson, London, UK, 5th edition, 2011.

[25] W. H. Price, "Factors influencing concrete strength," ACI Journal Proceedings, vol. 47, no. 2, pp. 417-432, 1951. 

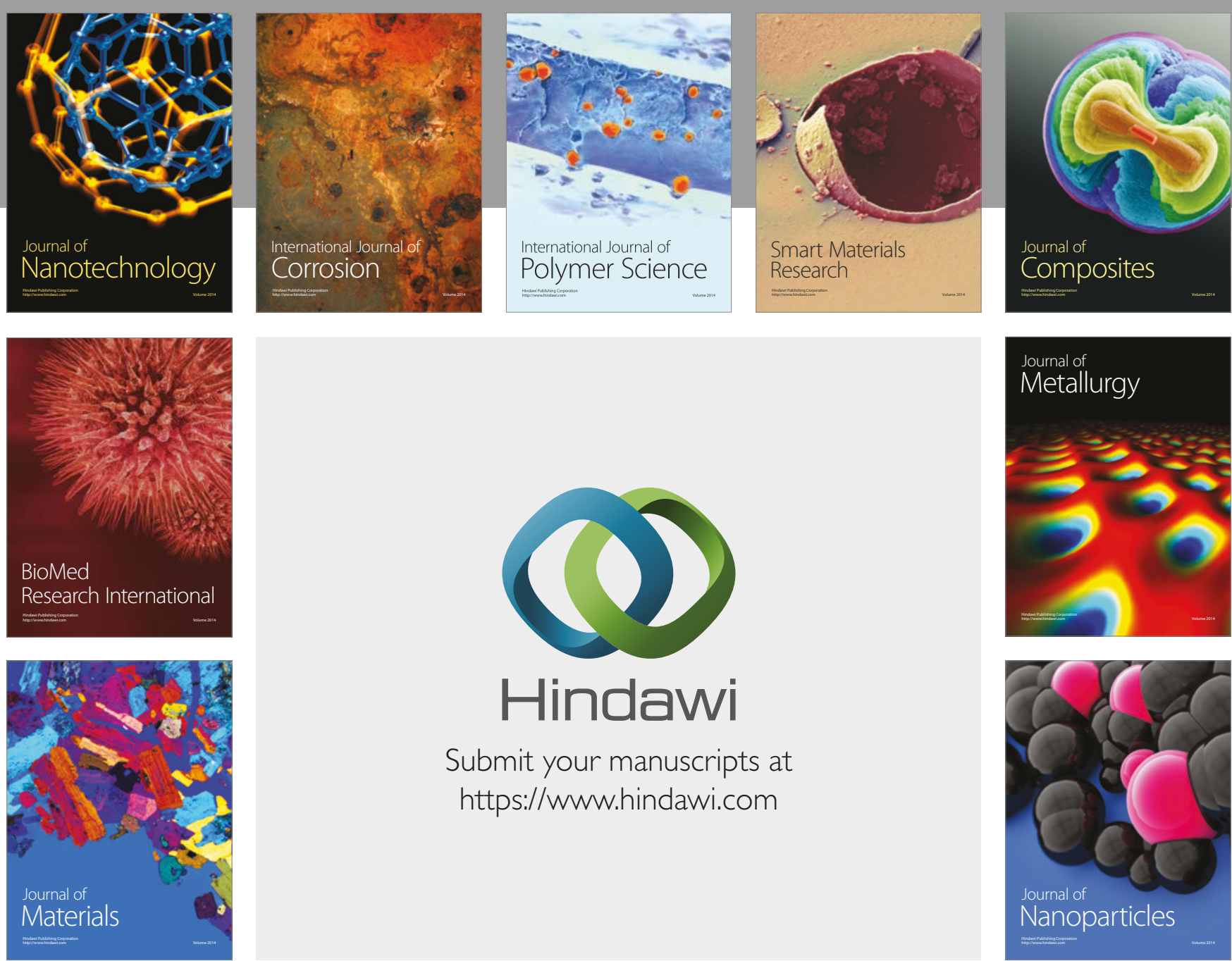

\section{Hindawi}

Submit your manuscripts at

https://www.hindawi.com
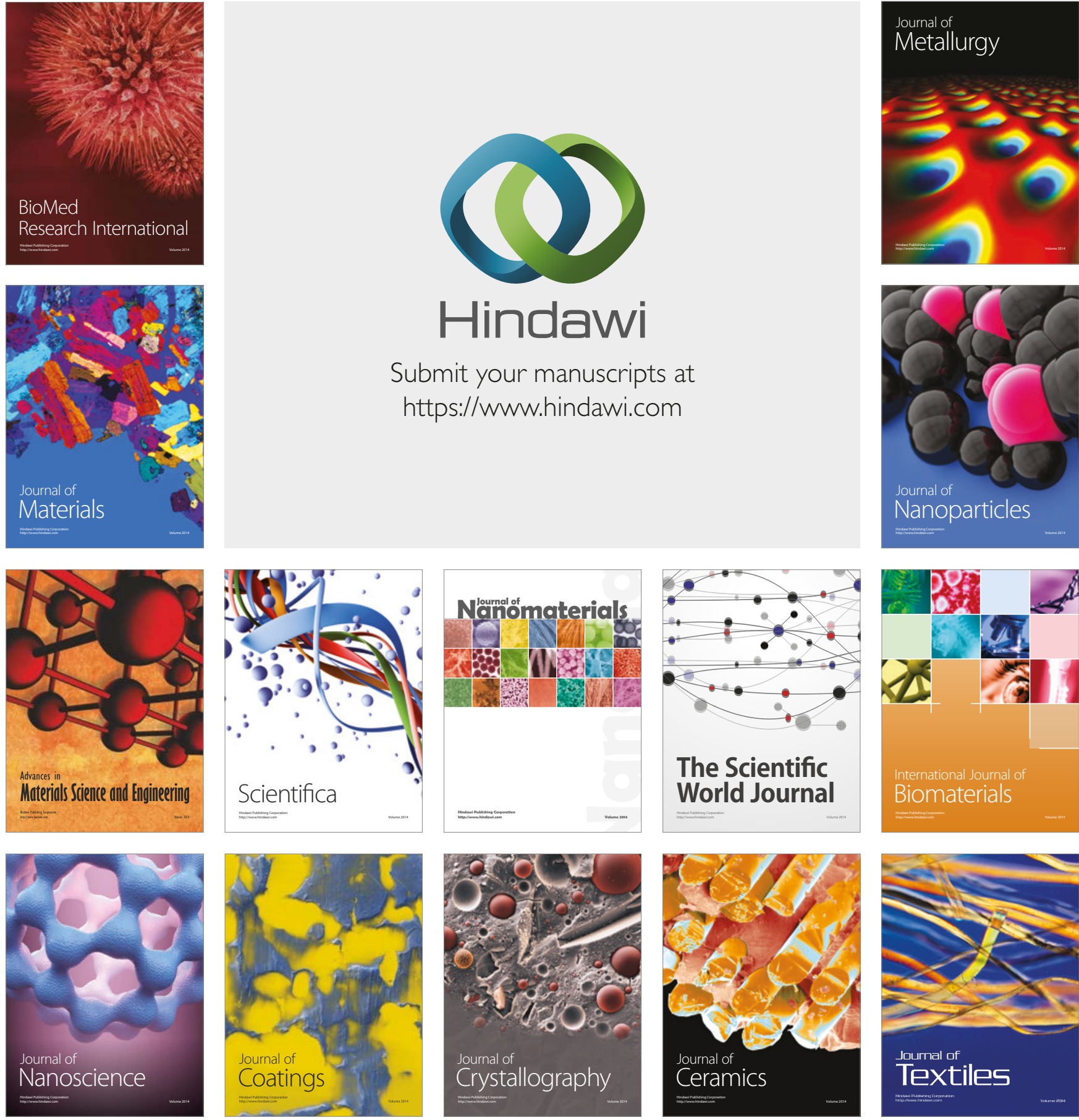

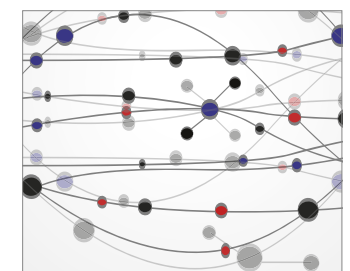

The Scientific World Journal
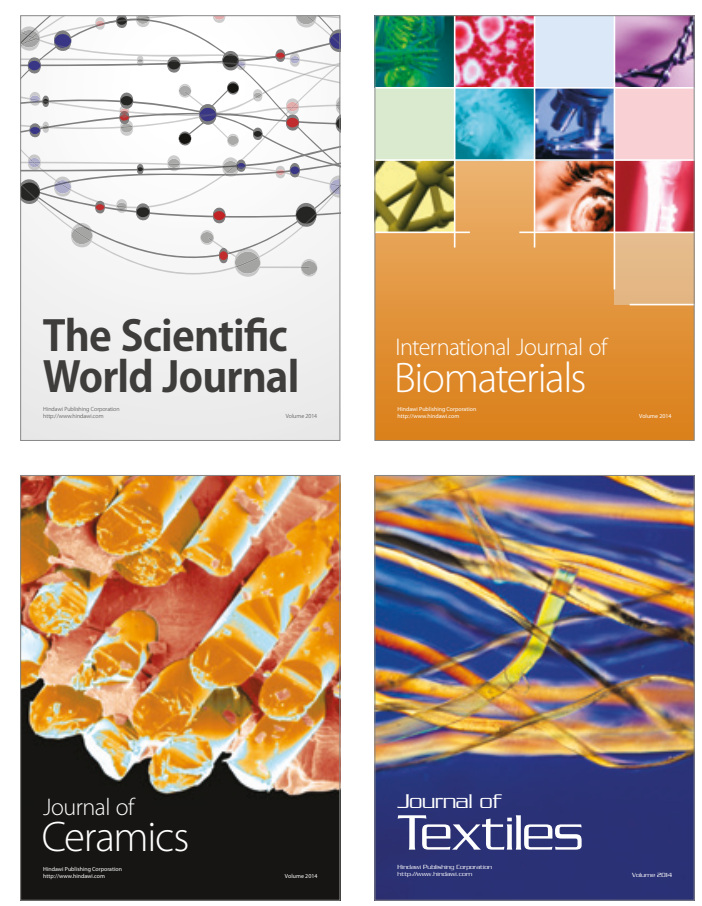